International Journal of Applied Engineering Research

ISSN 0973-4562 Volume 10, Number 10 (2015) pp. 25977-25994

(C) Research India Publications

https://dx.doi.org/10.37622/IJAER/10.10.2015.25977-25994

\title{
Mode Choice Behaviour of Commuters For Socio-Economic Analysis In Tiruchirappalli City
}

\author{
Dr. G. Elangovan ${ }^{\# 1}$ V.M.Rajanandhini ${ }^{\# 2}$ \\ \#1 Dean \\ \#2 Assistant Professor \\ Department of Civil Engineering, University College of Engineering, Thirukkuvalai, \\ Nagpattinam- 610 204, Tamil Nadu, India
}

\begin{abstract}
Economic activities and social well-beings in any urban area are very much dependent on the mobility provided by transportation system. But continuing increase in traffic congestion leads to motorist frustration, longer travel times, lost productivity, increased accidents and automobile insurance rates, more fuel consumption, increased freight transportation costs, and deterioration in air quality. As a result of the nation's growing population, increased levels of traffic congestion and environmental and energy concerns in many urban and suburban areas, more attention is being paid to public transport system. In the present scenario, considerable attention is being paid to strategic transport planning by way of mode choice modelling. 'modal choice' means the process by which the commuter chooses a mode of travel.

Hence an attempt is made to study mode choice behaviour of commuters for public transport system in Tiruchirappalli city as study area. The study is confined to analyse the choice between private bus and government bus from medium to long distance travel in Tiruchirappalli city. Based on the primary and secondary data collected in Tiruchirappalli city, this investigation presents the result of characteristics of the trip makers and their selection of mode in a new dimension of socio-economic background analysis by calculating the Origin and Destination Matrix (OD Matrix) for various bus routes, identifying the parameters which influence the passenger's opinion about the bus service, assessing the quality of the bus service through passenger opinion study, comparing the profile of State transport and private buses for suggesting recommendations towards improving the passenger satisfaction.
\end{abstract}

Keyword: Modal split Mode choice, Origin- Destination, Passenger Opinion, Utility, Trip makers. 


\section{Introduction}

Many metropolitan areas are plagued by rapid urbanization makes continuing increase in traffic congestion. The inadequate and insufficient public transport has compelled urban dwellers to use personal modes. Consequently, traffic congestion, longer travel times, motorist frustration, unsafe journey, increased accidents, automobile insurance rates, more fuel consumption, increased freight transportation costs, and environmental pollution resulting deteriorated air quality. Both, those with individual mode of transport and those dependent exclusively on public transport system have suffered in one way or the other. Though congestion, as most of other problems of modern life, is not new to urban areas, the problem is likely to be aggravated by the rapid growth and urbanization of human population.

\section{Mode Choice Analysis}

Aware of these serious consequences of traffic congestion, metropolitan areas are examining and implementing transportation congestion management (TCM) policies. Urban travel mode choice models provide the tool to evaluate the ability of such TCM policies to effect a change in mode from single-occupancy vehicles to high-occupancy vehicle modes. As a result of the nation's growing population, increased levels of traffic congestion and environmental and energy concerns in many urban and suburban areas, more attention has been paid to public transport system.

An important step in urban transportation planning is the prediction of travel demand by different modes of transport. The analysis of mode choice behaviour of urban travellers, in this regard will help in accurately predicting the mode wise demand for travel. Due to the recent significant rate of improvement in the economic status of people in developing countries, travel by personal modes like car and motorcycle is increasing faster in these countries REF [26].Recognizing cardependence problem as a pressing problem, travel mode choice has become an important area in transport policy. A lot of money and efforts have been put to use on promoting demand management measures to reduce car-use, however, the results have often been disappointing.

There are two terms 'mode choice' and 'modal split'. Mode choice refers to the process where the traveller chooses a particular mode for his trip. His choice of mode is made simultaneously with the decision to travel, the choice of destination and the route to be taken. Modal choice analysis is, therefore, the process of arriving at a decision about which mode to use in any particular circumstances. This type of analysis forms the basis to develop models of mode choice which are used to forecast the shares of private and public transport trips between roads and rapid transit systems. And the other term called 'modal split' is taken as the proportionate division of the total number of person trips between various means or mode of travel. Therefore, it can be expressed numerically as a fraction, or a number of fractions of the total trips; as a ratio; or as a percentage division between various modes such as car, railway, bus etc. Usually a basic distinction is made between private mode and mass or public transport. 
Hence there is a need to examine the demand for travel by these personal modes of travel as the increased use of these vehicles requires additional infrastructural facilities. In order to predict the future share of these personal vehicles, one must understand the present mode-choice behaviour of travellers. In this study, Tiruchirappalli city is considered for analysing mode choice behaviour because of this city is fast emerging as a prominent educational, commercial and trade centre having well established national/ international trade routes REF [4]. In this study, travel and mode choice behavior of commuters of different socio economic groups by calculating the Origin and Destination Matrix (OD Matrix) for various bus routes, identifying the parameters which influence the passenger's opinion about the bus service, assessing the quality of the bus service through passenger opinion study, comparing the profile of State transport and private buses for suggesting recommendations towards improving the passenger satisfaction.

\section{Case Study: Tiruchirappalli City}

Thiruchirappalli city is located at the central part of Tamil Nadu. It lies between $10^{\circ} 10^{\prime}$ and $11^{\circ} 20^{\prime}$ of the northern latitude $78^{\circ} 10^{\prime}$ and $29^{\circ} 0^{\prime}$ of eastern latitude and is the centre part of the Tamilnadu. It is having an area of 23.26 sq.kms with a population of 2418366 (2001 census). Thiruchirappalli city alone accounts for $80 \%$ of the urban population in the District and is experiencing a rapid growth in urban population. Figure 1 shows the flowchart for road network from Chatram bus stand for the study area under taken.

Tiruchirappalli City has a vast area extending over 23.25 sq. km, with a population of $24,18,366$ according to the 2001 census. The Thiruchirappalli city study corridor area map is shown in figure 2. There has been a phenomenal increase in the number of vehicles in this municipality which comprises of the regions like Srirangam, Golden rock and Thiruverumbur town ship in the past few years. Trichy and the neighboring municipal area have roads to a length of $250 \mathrm{~km}$; the density of traffic is extremely high in the stretches of Coleroom bridge, the Chatram Bus stand, St. Joseph college road, Market, Palakkarai, Thillainagar, Thennur, Woraiyur and Puthur roads. The roads in the town are narrow. Stretch from Cauvery bridge to the court and Palakkarai not permit even clear two line traffic. With the encroachments of the road, indiscriminate parking of vehicles, and stopping of buses in the roads has made driving in the town especially during peak hours, a slow and nightmarish experience. The parking of buses in the Chatram bus stand which incidentally is a main wide road through which cars, two wheelers etc, have to move towards Srirangam makes a chaotic. The geo referenced city bus route network of Thiruchirappalli is shown in Figure 3. 


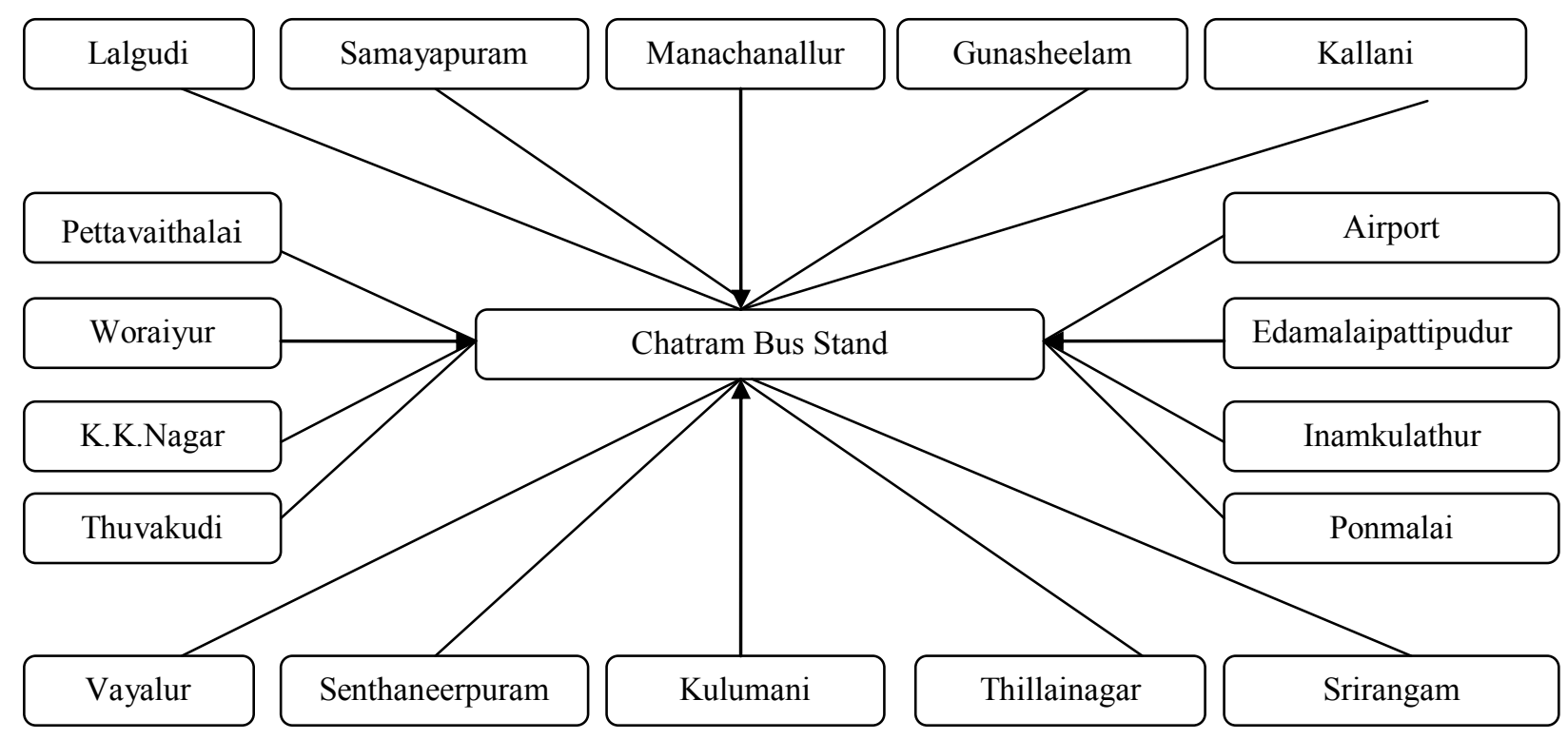

Figure 1: Flowchart For Road Network From Central Bus Stand

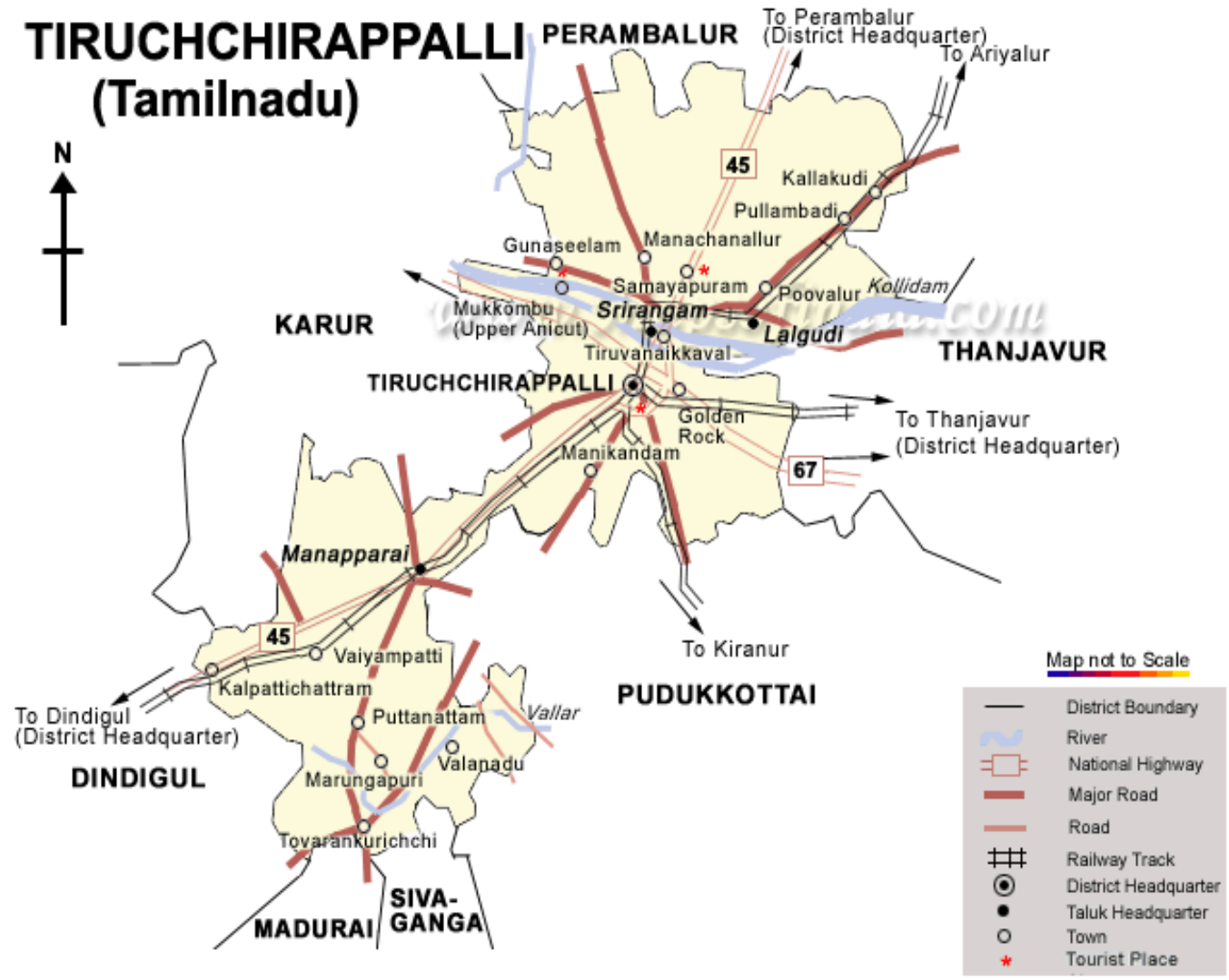

Figure 2: Study Corridor area Map of Thiruchirappalli City 
Mode Choice Behaviour of Commuters For Socio-Economic Analysis In et. al. 25981

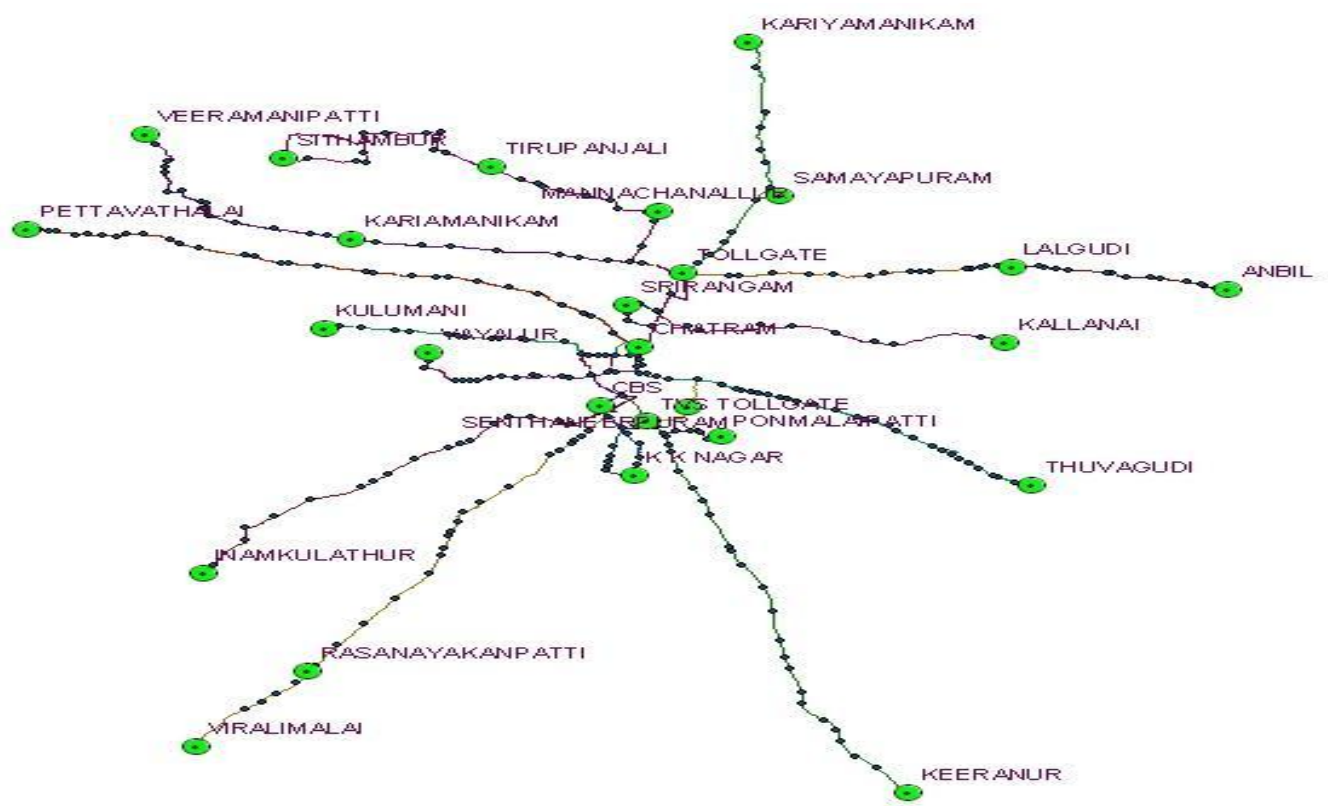

Figure 3: Geo referenced City Bus Network Map of Thiruchirappalli

\section{Methodology}

Figure.4 shows the methodology of carried out in Thiruchirappalli city for the entire study.

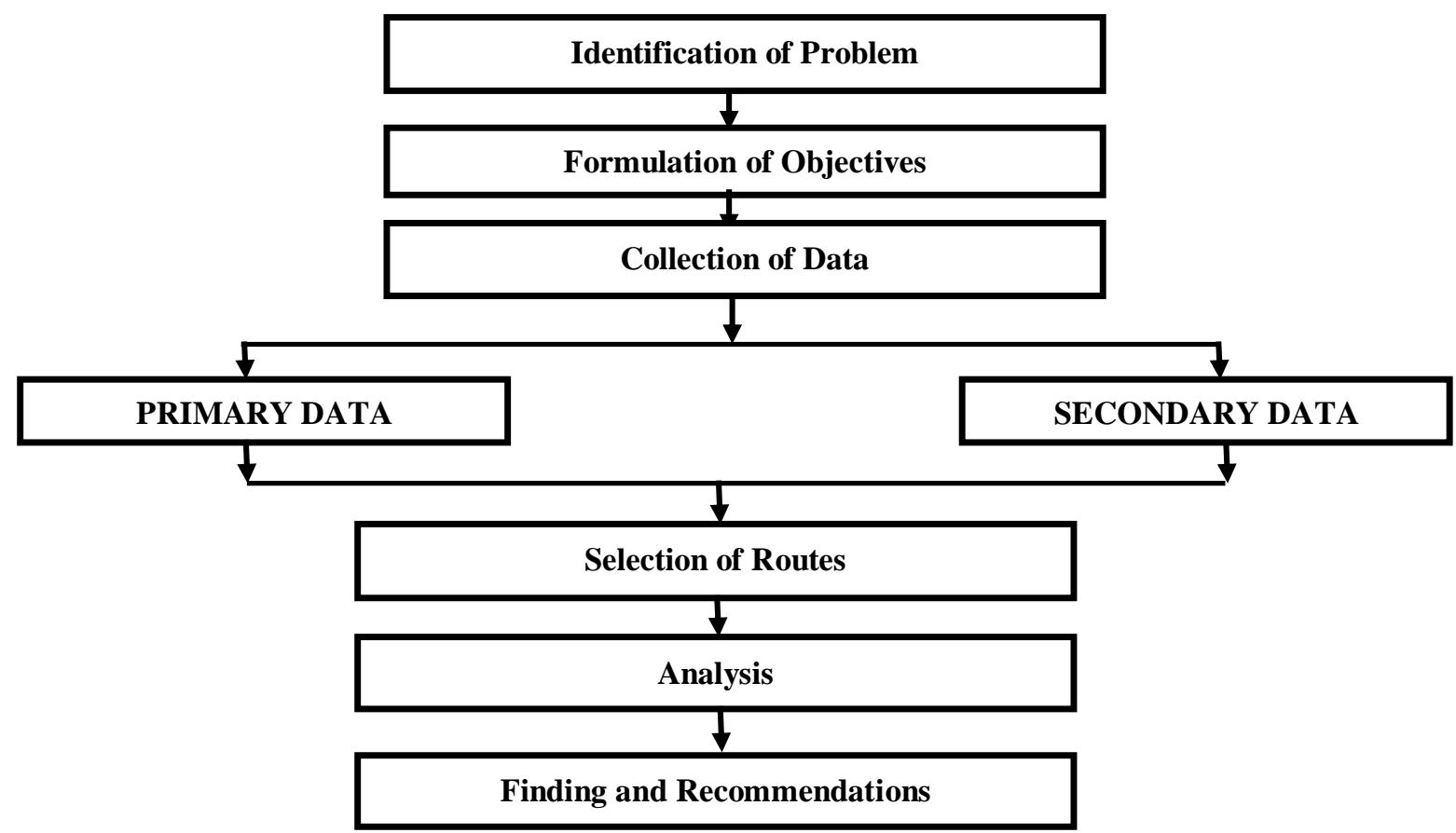

Figure 4: Flow Chart for Methodology 


\section{Questionnaire Design}

A pilot survey of sample size 100 was carried out after the preliminary design of a questionnaire. After studying the results of the survey, modifications were made to restructure some of the questions and the final questionnaire was prepared. Travel information was collected by putting suitable direct questions. Asking the questions systematically and recording the answers. Since this study concentrates on the travel characteristics by bus commuters who travel within $40 \mathrm{k} . \mathrm{m}$ in and around the city only were interviewed

The questionnaire consists of four parts.

- The first part is dealing with the personal level information about the commuter. In which the commuters are requested to give their details such as age, sex, income and vehicle ownership.

- The second part, stated preference survey questions have been included. It includes the opinion about the bus service, feeder mode of travel etc. have been included.

- Third part is dealing with the opinion about the city bus service of Tiruchirappalli city. It includes questions regarding the coverage provided by city bus service, opinion about punctuality, reliability and breakdowns of bus service, night service etc.

- Fourth part commuter's rating towards government bus and private bus.

- A five-point scale is incorporated in the questionnaire for the rating. The scale used is ranking performance level.

The commuters could be interviewed in different settings, namely, in their transit, work locations or in home. Interviewing at randomly selected households may not have sufficient number of commuters using different modes. In order to have sufficient number of samples, a large number of households will have to be approached. This will be again uneconomical and time consuming. So the final survey was carried out in the transits of Tiruchirappalli. The main advantages of interviewing the commuters in the transit due to they are coming to city from various parts of the town and this enable to cover all users of mode.

\section{Data Collection}

The Primary Survey (opinion survey) has been conducted for collecting primary data in Tiruchirappalli city to obtain the trip characteristics, the personal level information of commuters about the city bus service and rating of commuters towards private and government bus services.

The Secondary Survey has conducted to obtain bus route network data and passengers demand data as secondary data. The conductor's stastical data collected and from which the stage wise ticket sold details for all the nineteen sectors from Chatram bus stand in Tiruchirappalli city. From this data, the O-D matrix for each nineteen routes was formed and the number of passengers travelling in the bus. The number of passengers boarding and alighting in each stop along each route obtained from O-D matrix. 


\section{Data Analysis}

The data collected from the opinion survey such as the socio - economic characteristics, accessibility and trip maker's preferences etc. are analyzed. Also a comparison was made between State Transport Undertakings and the private service from the passengers view. The Socio-economic characteristics of bus passengers are analyzed considering several important factors such as profession, monthly income, vehicle ownership, trip purpose, origin, destination, distance from origin to destination and frequency of trip.

\section{A. Primary Data Analysis}

The data collected through the primary survey was analysed. In this study, a trip characteristic has been identified as a movement for specified purposes from origin and destination. The analysis of the travel information gathered through opinion survey is analysed. The Sample of results is obtained in the following figures.

\section{1) Personal Level Information Analysis:}

The personal level details include the sample distribution based on age, sex, profession and monthly income. The trip purpose, distance from origin to destination and frequency of trips are also analysed. Figures $5 \& 6$ sample of Personal Level Information Analysis results are shown as below.

\section{1) Trip Characteristics:}

Work trips are more than non-work trips. Work trips contribute $52 \%$ of total trips. As per figure. 5 about $24 \%$ of the trips are educational. The remaining trips of altogether (Business, social, Health Shopping, Recreational and others) contribute 24\% of the total trip.

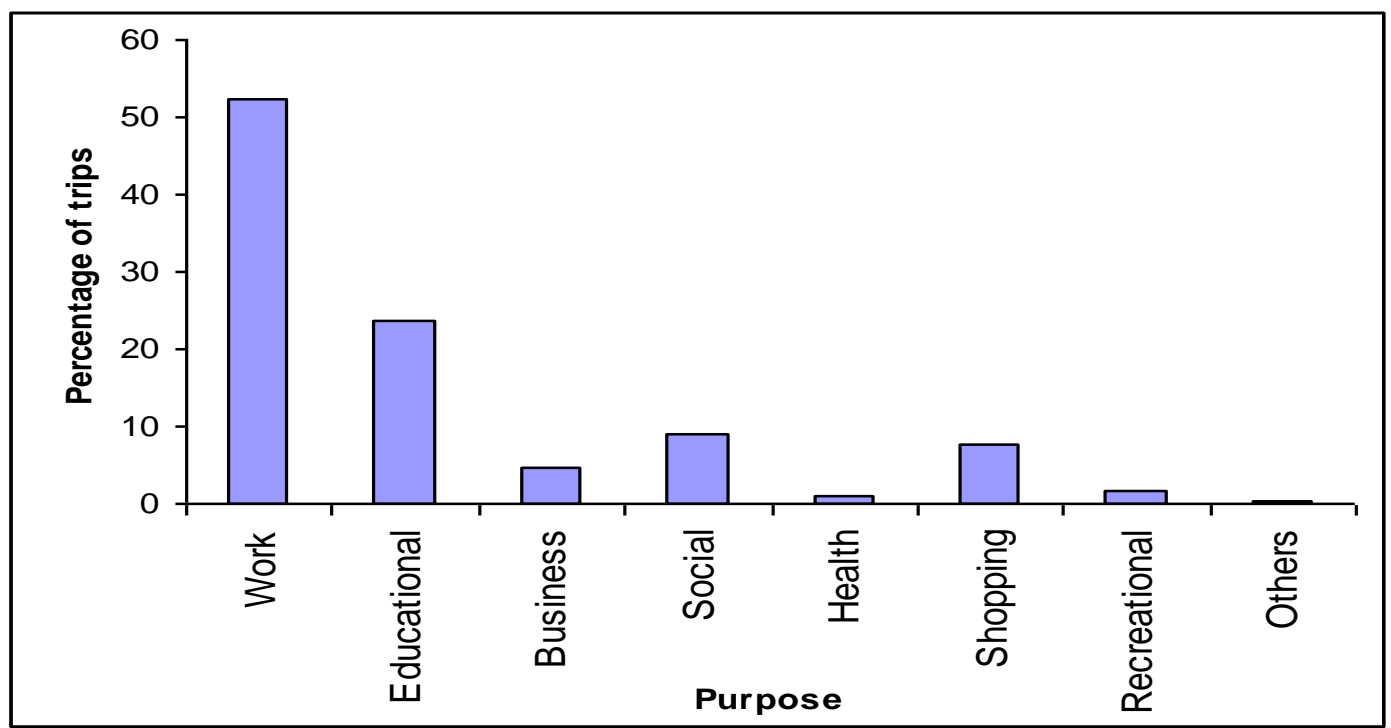

Figure 5; shows the percentage of trips done for different purposes at the study area stretch by bus stop 


\section{2) Distance from Origin to destination:}

As the city trips maximum distance of $30 \mathrm{~km}$, most of the trips are within the range of 15 to $20 \mathrm{~km}$. A graph is drawn between the distance and the percentage of trips and is shown in figure 6 .

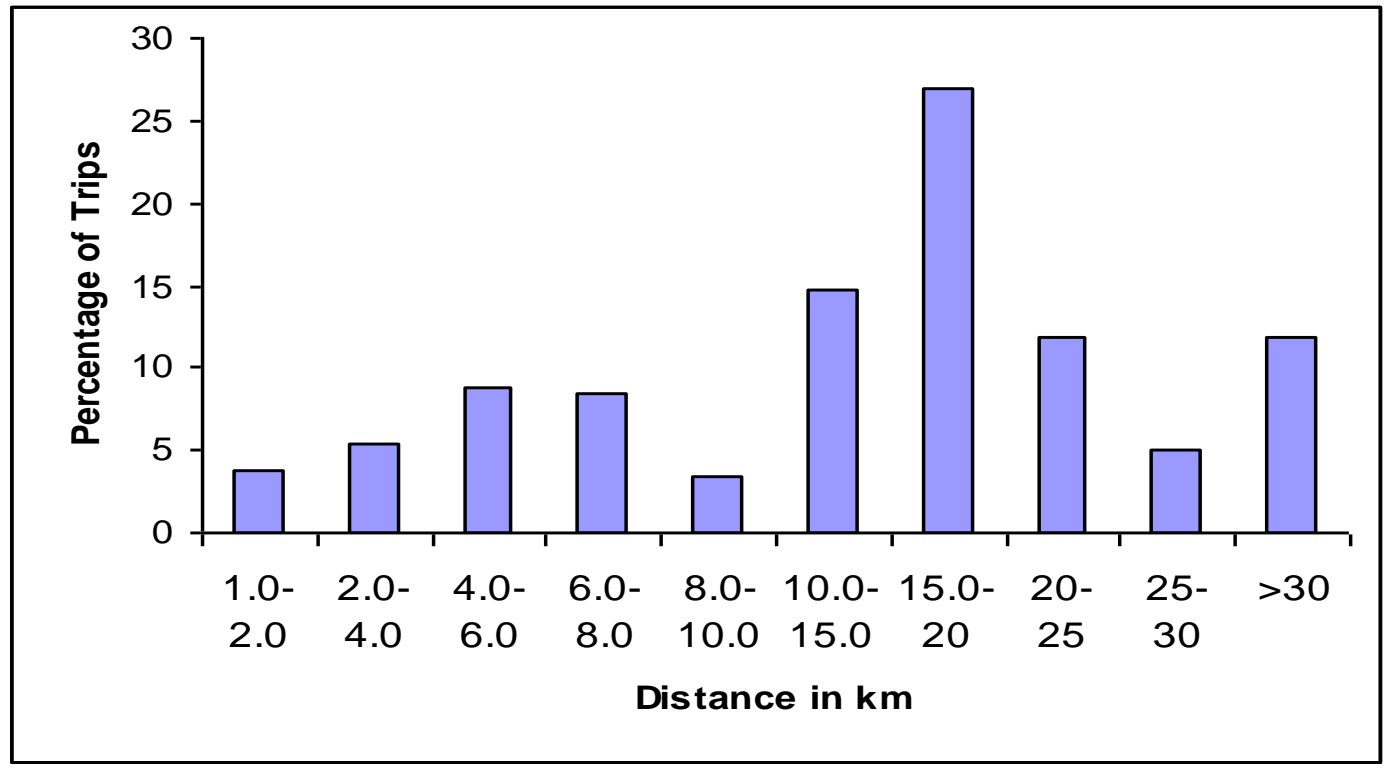

Figure 6: Distance vs Percentage of Trips

2) Accessibility and Trip Maker's Preferences:

Accessibility and trip maker's preferences comprise walking time to the bus stop, waiting time in the bus stops preference of bus. Figures $7 \& 8$ sample of Accessibility and Trip Maker's Preferences analysis results has shown as below.

\section{1) Waiting Time in the bus stop:}

About $80 \%$ of the passengers are sparing less than 10 minutes for a bus in the bus stop. A lesser percentage spent more than 15 minutes which indicates that sufficient buses are operated in the city. Figure 7 shows the relation between waiting time and percentage of trips. Waiting time in the peak and off peak period is also shown in figure 8. From Figure. 8 it can be concluded that the waiting time is less in peak periods than in off peak periods. 


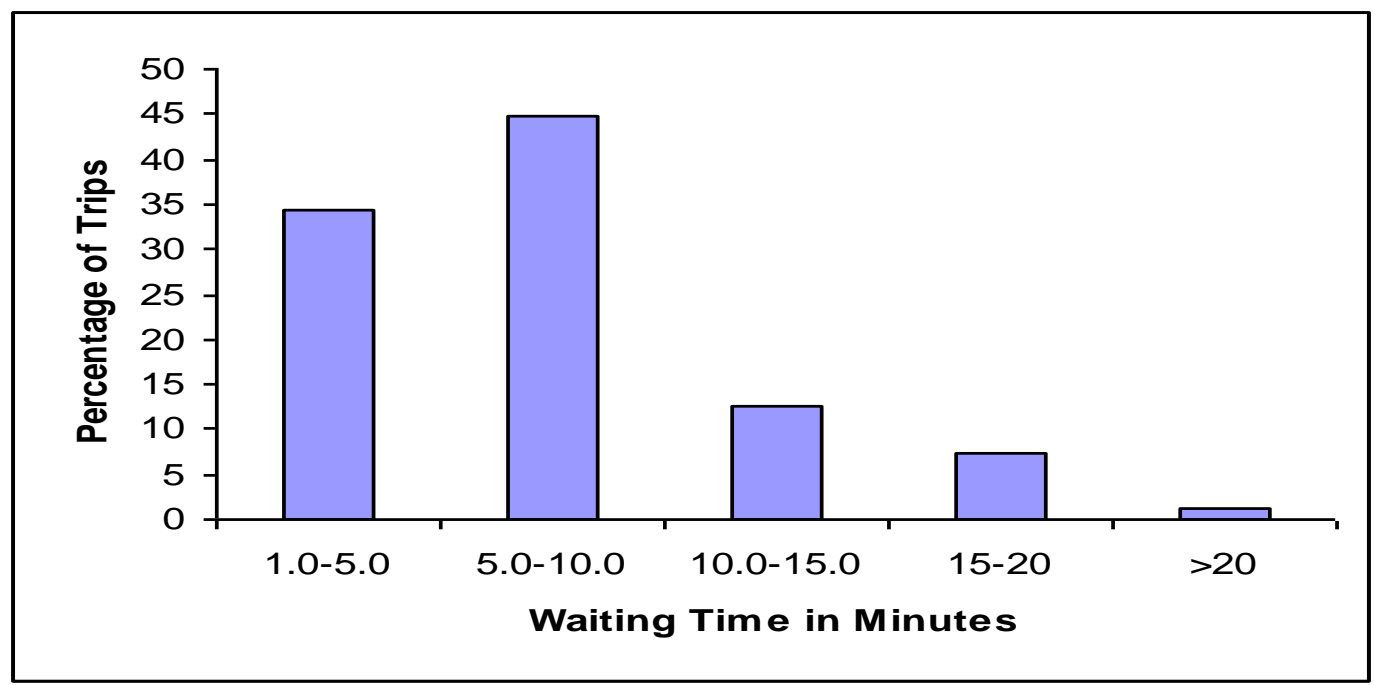

Figure 7: Shows the percentage of trips by the waiting time

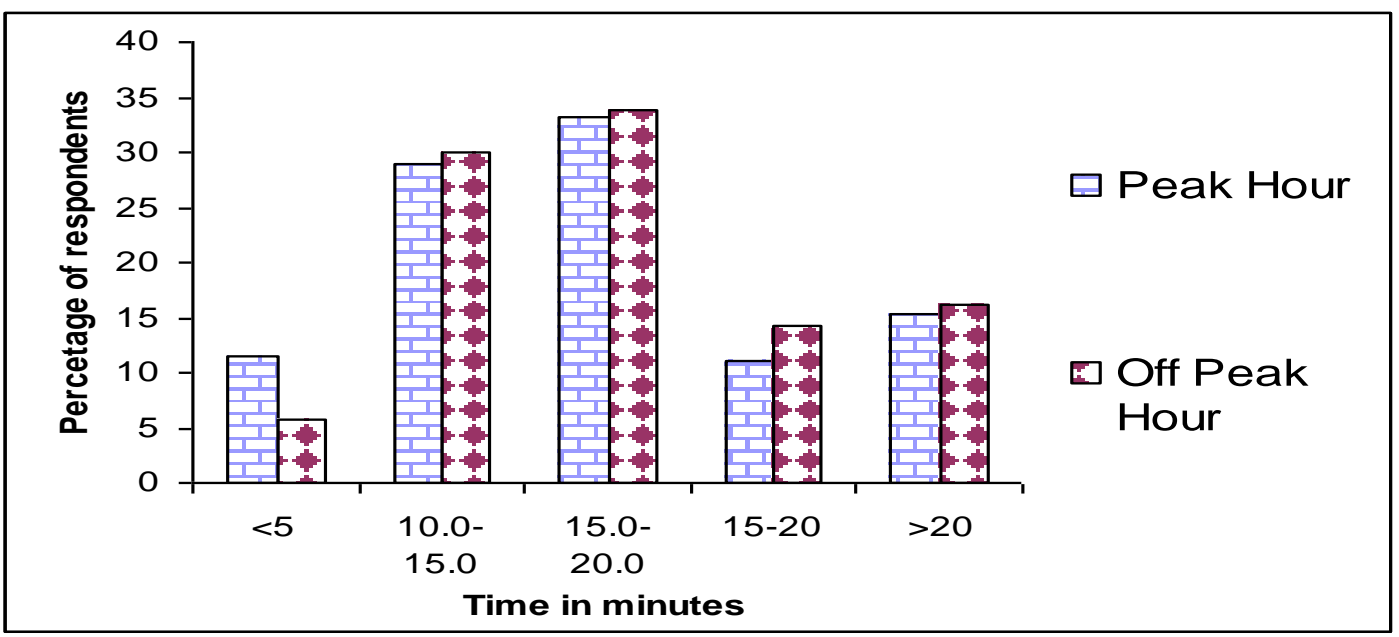

Figure 8: Waiting Time in Peak and Off Peak Periods

3) Opinion about the City Bus Service:

Opinion about the coverage provided by the bus service, night service and punctuality about the bus service are also analysed.

\section{1) Opinion about Bus Service:}

From the survey it has obtained that $47 \%$ of the respondent's opinion about Tiruchirappalli Bus service is satisfactory because of the easy availability of bus and cheap cost. Only $6 \%$ of respondent's opinion is that the bus service very good.Around $2 \%$ of the respondents opinion is that service is very bad.Opinion about bus service is shown in figure 9. 


\section{$16 \% \quad 1 \% \quad 2 \%$}

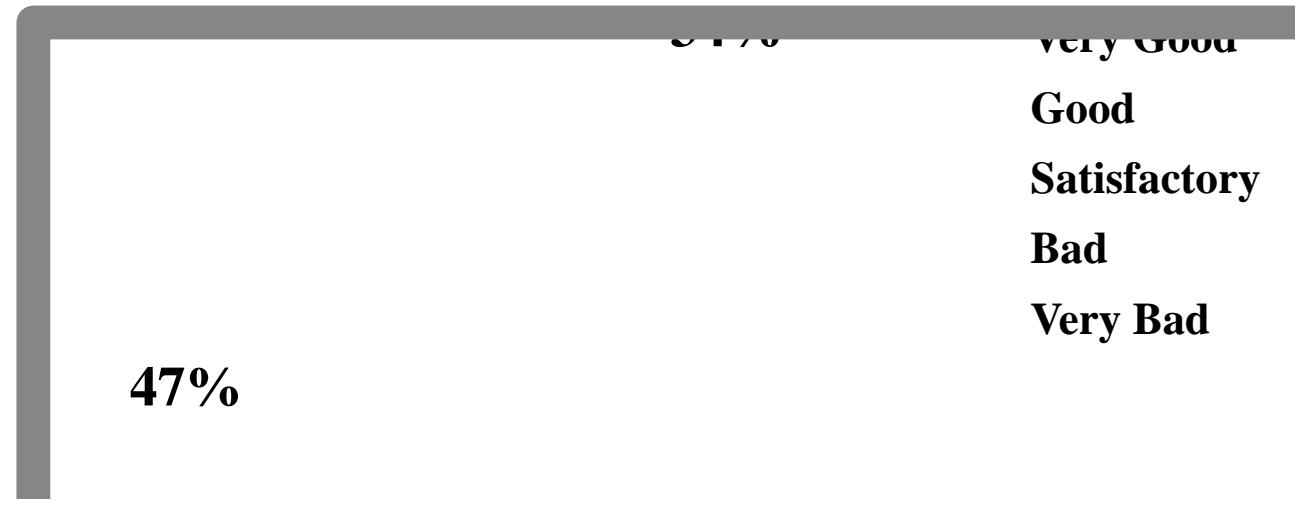

Figure 9: Shows the Opinion about Coverage Provided by the Bus Service

\section{2) Relation between Socio- Economic Characteristics:}

In this study, a comparis on has been made between socio economic characteristics of bus passengers. The following three alternate systems were formulated.

$\begin{array}{llll}\text { System-I } & \text { Income } & \text { vs } & \text { vehicle ownership } \\ \text { System - II } & \text { Profession } & \text { vs } & \text { Frequency of trip } \\ \text { System - III } & \text { Trip purpose } & \text { vs } & \text { Frequency of trip }\end{array}$

In Tiruchirappalli, the trip rate by bus has variation with income. People having income in the range Rs.5000-10000 using the bus more. As the income increases the choice of mode shifts from public to personalized transport.

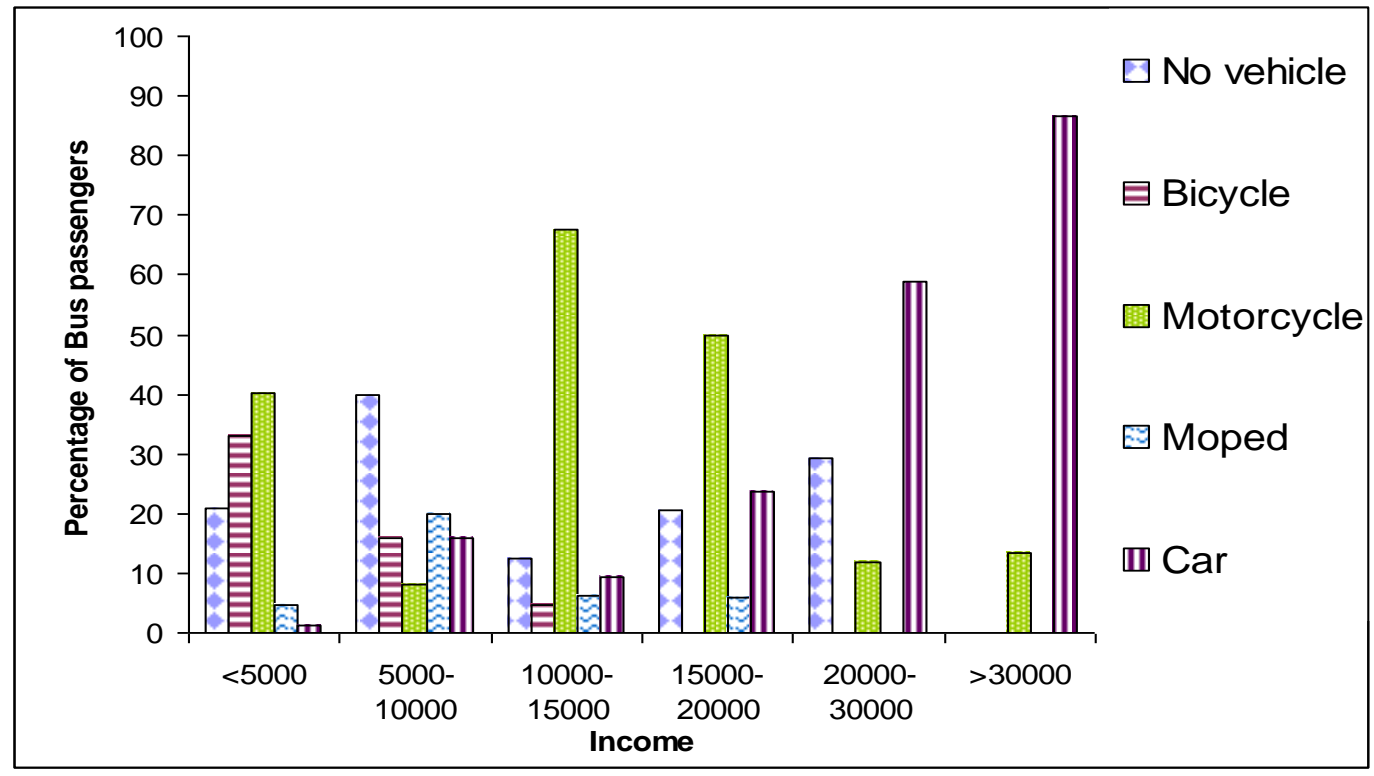

Figure 10: Income Vs Vehicle Ownership 
Work trips are more in Tiruchirappalli city. Private industry employees are using the bus more. Next to work trips educational trips are more.

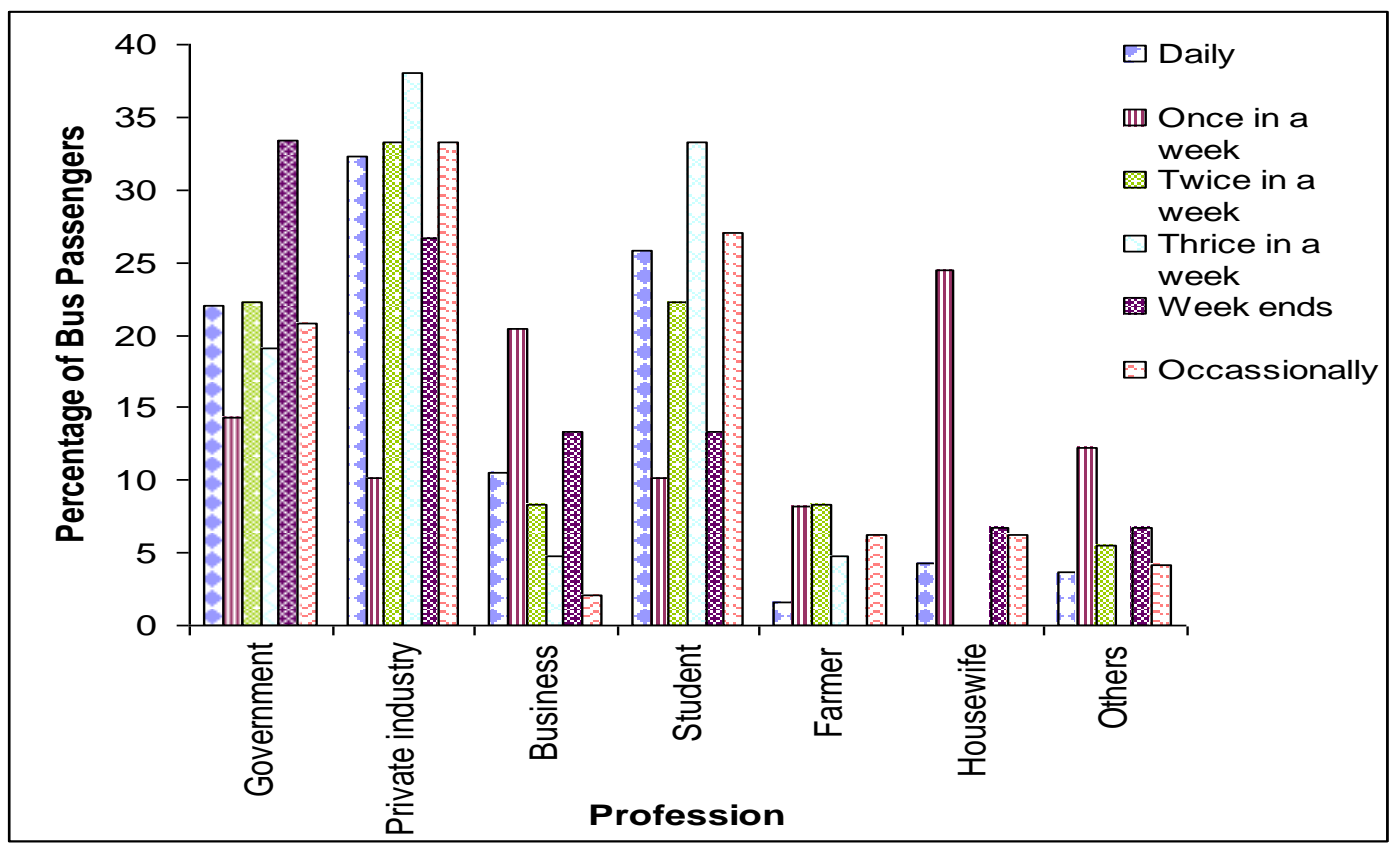

Figure 11: Profession Vs Frequency of Trip

The working category makes the highest number of single trips in a day, while those are from shopping purpose category makes only occasional trips.

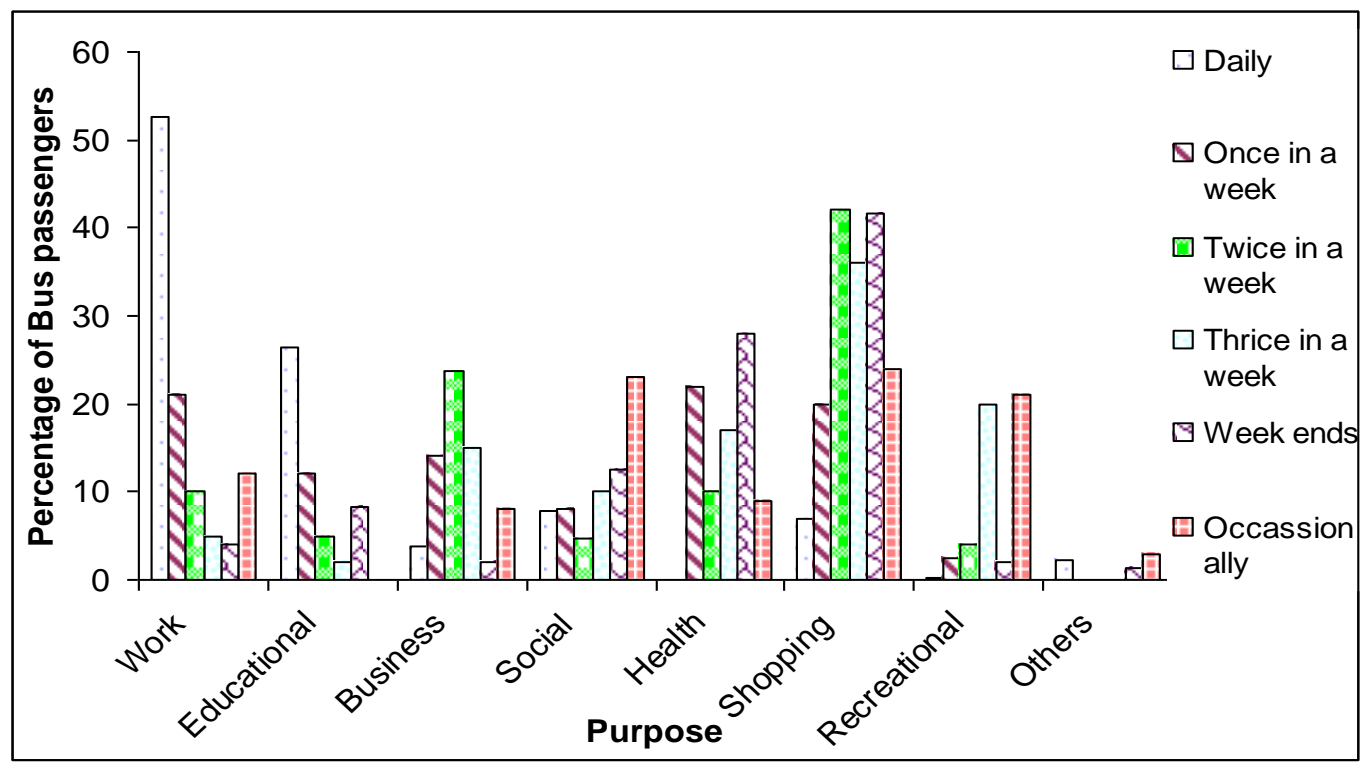

Figure 12: Trip Purpose Vs Frequency of Trip 
4) Comparison between private bus and government bus:

In this part of comparison, the existing facilities in the buses like width of entrance or exit, step height from ground level, width of seat, and path space between rows of seats were discussed.

\section{1) Preference of Bus:}

About $54 \%$ of the passengers prefer the private bus whereas $46 \%$ of the passengers prefer the government bus as seen from figure 15. Opinion about Government and private bus is graphically presented in figures 13 and 14 .

\section{$4 \% \quad 1 \%$}

$15 \%$

$22 \%$

\section{Very Good \\ Good \\ Satisfactory}

Bad

Very Bad

\section{$\mathbf{5 8 \%}$}

Figure 13: Opinion about Govt. Bus Service

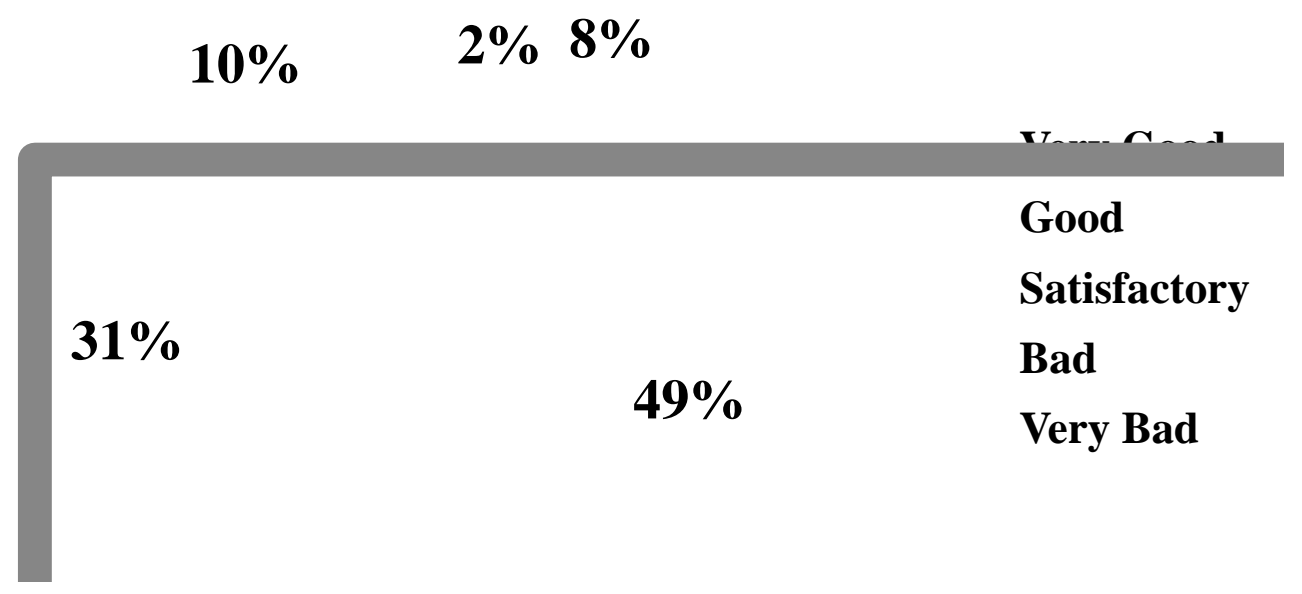

Figure 14: Opinion about Private Bus Service 


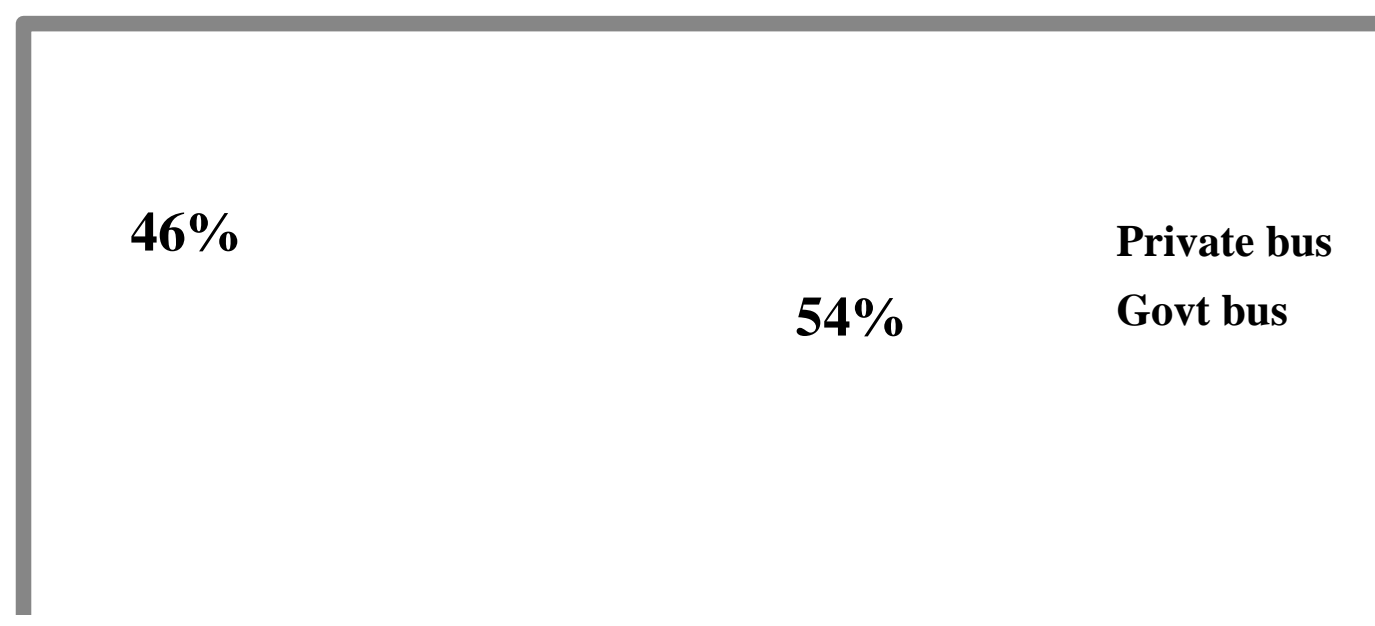

Figure 15: Preference of Bus

\section{B. Secondary Data Analysis}

The data collected through the secondary survey was analysed .In order to find boarding and alighting at bus stops and link volume in between the bus stops it is required to assess the OD for bus trips. OD matrix for bus trip is calculated from the conductor's stastical. The number of passengers boarding and alighting in each stop along each route is also obtained. The study has been limited to analysis of trips made from Chatram bus stand to various sectors and vice versa. The Secondary data results are obtained in the following table 4.

\section{1) Bus Services in Tiruchirappalli:}

Trichy is well connected to various parts of Tamilnadu, by private, and government run bus services. The Thappakulam bus stand, near Rock Fort temple, runs local, and mofussil bus serivces, that connect people to nearby towns and villages. Bus services are frequent, once every two to five minutes, and this public transport moves the whole of Trichy, and its heavily subsidized by the government.. The details of city buses operated in Trichy are shown in table 1

In order to find boarding and alighting at bus stops and link volume in between the bus stops it is required to assess the OD for bus trips. OD matrix for bus trip is calculated from the conductor's statistical. The number of passengers boarding and alighting in each stop along each route is also obtained. The study has been limited to analysis of trips made from Chatram bus stand to various sectors. The O-D matrix developed has been given in tables 2 and 3. From these OD matrices it can be found that the trips are more in Chatram bus stand to Samayapuram, Pettavaithalai, K.K Nagar, Thuvakudi, Ponmalai and Senthaneerpuram routes. 
Table 1: Details of City Buses Operating In Thiruchirappalli City

\begin{tabular}{|c|c|c|c|c|c|c|c|c|c|}
\hline \multirow{2}{*}{$\begin{array}{l}\text { Sl. } \\
\text { No }\end{array}$} & \multirow{2}{*}{ Sector } & \multirow{2}{*}{ RF I } & \multirow{2}{*}{ RF II } & \multirow{2}{*}{ CNT } & \multirow{2}{*}{ LAL } & \multicolumn{2}{|c|}{$\begin{array}{ll}\begin{array}{l}\text { State } \\
\text { Bus }\end{array} & \text { Transport } \\
\end{array}$} & \multicolumn{2}{|c|}{ Private Bus } \\
\hline & & & & & & Vehicles & Singles & Vehicles & Singles \\
\hline 1 & Lalgudi & - & - & - & 29 & 29 & 307 & 6 & 122 \\
\hline 2 & Samayapuram & 100 & 100 & 1 & 21 & 23 & 281 & 13 & 224 \\
\hline 3 & Manachanallur & 4 & 7 & - & - & 11 & 172 & 7 & 130 \\
\hline 4 & Gunasheelam & 4 & 3 & - & - & 7 & 82 & 3 & 28 \\
\hline 5 & Kallani & 2 & - & 3 & - & 5 & 95 & 3 & 35 \\
\hline 6 & Pettavaithalai & 2 & 8 & - & - & 10 & 141 & 6 & 92 \\
\hline 7 & Woraiyur & 4 & 6 & 5 & - & 15 & 274 & 8 & 256 \\
\hline 8 & K.K.Nagar & 11 & - & 10 & - & 10 & 216 & 5 & 26 \\
\hline 9 & Thuvakudi & 22 & 9 & 1 & 32 & 31 & 219 & 36 & 580 \\
\hline 10 & Ponamalaipatti & - & - & 5 & - & 9 & 114 & 7 & 68 \\
\hline 11 & Ponmalai & - & 4 & 5 & - & 9 & 171 & 7 & 142 \\
\hline 12 & Airport & - & - & 9 & - & 9 & 138 & 7 & 116 \\
\hline 13 & Edamalaipattipudur & - & - & 11 & - & 11 & 198 & 9 & 174 \\
\hline 14 & Inamkulathur & - & - & 11 & - & 11 & 198 & 3 & 58 \\
\hline 15 & Vayalur & 5 & 7 & - & - & 12 & 176 & 10 & 176 \\
\hline 16 & Senthaneerpuram & - & - & 2 & - & 2 & 60 & 2 & 56 \\
\hline 17 & Kulumani & - & 3 & - & - & 3 & 44 & 7 & 108 \\
\hline 18 & Thillainagar & 2 & - & 2 & - & 4 & 128 & - & 11 \\
\hline 19 & Srirangam & 1 & - & 10 & - & 11 & 288 & 15 & 500 \\
\hline & Total & 62 & 55 & 63 & 30 & 210 & 3302 & 151 & 2911 \\
\hline
\end{tabular}

Table 2: Bus OD Matrix for Chatram Bus Stand to Srirangam

\begin{tabular}{|l|c|c|c|c|c|}
\hline $\begin{array}{l}\text { Name of the } \\
\text { stops }\end{array}$ & M.G.Gate & Annasilai & T.V.Koil & Srirangam & Total \\
\hline M.G.Gate & 0 & 420 & 574 & 784 & 1778 \\
\hline Anna Silai & & 0 & 280 & 448 & 728 \\
\hline T.V.Koil & & & 0 & 98 & 98 \\
\hline Srirangam & & & & 0 & 0 \\
\hline Total & 0 & 420 & 854 & 1330 & 2604 \\
\hline
\end{tabular}

Table 3: Bus OD Matrix For Srirangam To Chatram Bus Stand

\begin{tabular}{|l|c|c|c|c|c|}
\hline Name of the stops & Srirangam & T.V.Koil & Anna Silai & M.G.Gate & Total \\
\hline Srirangam & 0 & 280 & 406 & 0 & 686 \\
\hline T.V.Koil & & 0 & 224 & 238 & 462 \\
\hline Anna Silai & & & 0 & 322 & 322 \\
\hline M.G.Gate & & & & 0 & 0 \\
\hline Total & 0 & 280 & 630 & 560 & 1470 \\
\hline
\end{tabular}


Table 4: The Secondary Data Results

\begin{tabular}{|c|c|c|}
\hline Sl. No. & Route & Total \\
\hline 1 & Chatram Bus Stand to Lalgudi & 2198 \\
\hline 2 & Lalgudi to Chatram Bus Stand & 2121 \\
\hline 3 & Chatram Bus Stand to Samayapuram & 4837 \\
\hline 4 & Samayapuram to Chatram Bus Stand & 3717 \\
\hline 5 & Chatram Bus Stand to Manachanallur & 763 \\
\hline 6 & Manachanallur to Chatram Bus Stand & 728 \\
\hline 7 & Chatram Bus Stand to Gunasheelam & 1448 \\
\hline 8 & Gunasheelam to Chatram Bus Stand & 976 \\
\hline 9 & Chatram Bus Stand to Kallani & 2037 \\
\hline 10 & Kallani to Chatram Bus Stand & 1514 \\
\hline 11 & Chatram Bus Stand to Pettavaithalai & 3441 \\
\hline 12 & Pettavaithalai to Chatram Bus Stand & 2370 \\
\hline 13 & Chatram Bus Stand to K.K.Nagar & 8379 \\
\hline 14 & K.K.Nagar to Chatram Bus Stand & 7947 \\
\hline 15 & Chatram Bus Stand to Thuvakudi & 3672 \\
\hline 16 & Thuvakudi to Chatram Bus Stand & 3564 \\
\hline 17 & Chatram Bus Stand to Ponmalai & 9945 \\
\hline 18 & Ponmalai to Chatram Bus Stand & 7170 \\
\hline 19 & Chatram Bus Stand to Airport & 2282 \\
\hline 20 & Airport to Chatram Bus Stand & 2093 \\
\hline 21 & Chatram Bus Stand to Inamkulathur & 6030 \\
\hline 22 & Inamkulathur to Chatram Bus Stand & 5493 \\
\hline 23 & Chatram Bus Stand to Vayalur & 4564 \\
\hline 24 & Vayalur to Chatram Bus Stand & 2163 \\
\hline 25 & Chatram Bus Stand to Senthaneerpuram & 6776 \\
\hline 26 & Senthaneerpuram to Chatram Bus Stand & 7311 \\
\hline 27 & Chatram Bus Stand to Kulumani & 3763 \\
\hline 28 & Kulumani to Chatram Bus Stand & 3223 \\
\hline 29 & Chatram Bus Stand to Srirangam & 2604 \\
\hline 30 & Srirangam to Chatram Bus Stand & 1470 \\
\hline
\end{tabular}

The results of the analysis based on income, vehicle ownership and trip purpose are given below:

- Work trips are more in Tiruchirappalli city. Private industry employees are using the bus more. Next to work trips educational trips are more.

- The working category makes the highest number of single trips in a day, while those are from shopping purpose category makes only occasional trips.

- In Tiruchirappalli, the trip rate by bus has variation with income. People having income in the range Rs.5000-10000 using the bus more. As the income increases the choice of mode shifts from public to personalized transport. 
- The trip lengths were found to be more in the range of 10-20 k.m.

- When compared to other cities in Tamilnadu the frequency and availability of buses are more in Tiruchirappalli city.

- Because of high fuel cost and parking difficulty commuters are preferring bus than own vehicle.

- Commuters are giving more importance to journey time and waiting time in bus stop cost.

- Most of the passenger's opinion about Tiruchirappalli city bus service is satisfactory.

- During off peak hour the frequency of bus is less as comparing to peak hour frequency. In order to satisfy the unemployed and housewives, off peak hour frequency has to be increased.

- Most of the passengers stated that the night service is not good.

- People prefer to travel by private bus than by Government bus because of cleanliness, rare breakdowns and good appearance.

\section{Conclusion}

Based on the primary and secondary data analysis made in Tiruchirappalli city, the following major conclusions are drawn and presented.

Analysis of the opinion of the bus passengers shows that, the improvement in the quality of both the Government and Private services is the need of the hour. It is observed that in terms of the parameters like safety of passengers and crew behaviour State Transport Undertaking buses are rated better. On the other hand private buses are rated better in cleanliness, breakdowns and noise during journey. Based on the surveys the suggestions made by the respondents are cleanliness has been found to be lacking in Government buses, hence the vehicle may be periodically cleaned and maintained. More passengers opined that the private buses are running at very high speed when compared to Government buses. Suitable management measures can be taken to bring down to speed to the passenger's satisfaction level.

\section{References}

[1] Ajibade Ogunjumo and Adeyemi Fagbemi (2002) "Towards modal choice decision-making models: A case study of Lagos state transport corporation bus riders" Transportation Research Part A: General ,Volume 25, November, pp. 391-397.

[2] Gang LIU (2006.) "A behavioral model of work-trip mode choice in Shanghai" China Economic Review, November.

[3] Geetam Tiwari (2003) "Bicycle - As a feeder mode for bus service", Journal of Transport Economics and Policy, September.

[4] Dr. Indrasen Singh (2001) "Analysis of commuter's mode choice attitude in Delhi Metroplitan City", Indian Highways, November. 
[5] Jiao Pengpeng etal (2006) "Disaggregate Traffic Mode Choice Model Based on Combination of Revealed and Stated Preference Data", Tsinghua Science And Technology, Volume 11, Number 3, June, pp.351-356.

[6] John Pucher and John L. Renne (2005) "Urban-Rural Differences in Mobility and Mode Choice", Journal of Transport Economics and Policy, April.

[7] John Thogersen(2006) "Understanding Repetitive Travel Mode Choices In A Stable Context: A Panel Study Approach", Transportation

[8] Research part A: Policy and Practice, Volume 40, October, pp. 621-638.

[9] Joseph S. DeSalvo and Mobinul Huq (2005) "Mode Choice, Commuting Cost, and Urban Household Behavior", Journal of Regional Science, Volume 45, August, pp. 493.

[10] Madan D.B and R. Groenhout (1987) "Modelling Travel Mode Choice for the Sydney Work Trip", Journal of Transport Economics and Policy, , Vol. 21, No. 2, May, pp. 135.

[11] McCarthy P.S (1977) "Residential Location and the Journey to Work. An Empirical Analysis", Journal of Transport Economics and Policy, Vol. 11, No. 2, May, pp. 169.

[12] Narisa Limtanakool (2005) "The Influence of Socioeconomic Characteristics Land Use and Travel Time Considerations on Mode Choice for Medium and Longer Distance Trips", Journal of Transport Geography, Volume 14, September, pp. 327-341.

[13] Ponnuswamy.S, Anantharajan.T (1992) "Modal Choice in Madras", Indian Hihways, January.

[14] Quarmby D.A (1967) "Choice of Travel Mode for the Journey to Work: Some Findings" Journal of Transport Economics and Policy, September, Vol. 1, No. 3, pp. 273.

[15] Shiftan Yoram and Barlach Yotam (1974) "Effect of employment site characteristics on commute mode choice" Transportation research record.

[16] Tim Schwanen and Patricia L. Mokhtarian (2005) "What affects commute mode choice neighborhood physical structure or preferences toward neighborhoods", March 2005, pp. 83-99.

[17] Ulberg (1989) "Psychological Aspects of Mode Choice" Journal of Transport Economics and Policy, December.

[18] Virendra Kumar, Khanna S.K (1984) "Validation of inter City Mode Choice Disaggregate Model" Indian Highways, June.

[19] Dr. Sarna A.C, Dr. Sarin S.M (1985) "Transportation Planners DilemmaModal Split and its manipulation" Indian Highways, January

[20] Dr. Raghava Chari S (1982) "Modal Split models for Work Trip Travel", Indian Highways, Volume 10, pp 18-22.

[21] Anu P Alex (2003) "Travel and Mode Choice Behaviour of Trip MakersA Comparative study of Tamilnadu and Kerala", M.Tech Thesis.

[22] Muralidharan R (2005) "Traveller Information System for Public Transport Buses In Tiruchirappalli City Using Gps”, M.Tech Thesis. 
[23] Ben-Akiva, M. and Lerman, S.R. (1985) "Discrete Choice Analysis: Theory and Application to Travel Demand", MIT Press, Cambridge,MA.

[24] Juan de Dios Orthuzarand Luis G Willumseen (1995) "Modelling Transport".

[25] Kadiyali L R (1991) “Traffic Engineering \& Transport Planning” Khanna Publishers, New Delhi.

[26] Papacostas C.S (1987) "Fundamentals of Transportation Engineering".

[27] V.Thamizh Arasan. "Mode choice for work journeys of urban travellers owning motorized vehicles in India", Transportation Planning and Technology, 7/1998.

[28] Tiruchirappalli district map [online]. Available: http // tiruchian.wordpress.com/maps. 